\title{
The Relationship Between Development Trajectories of Resilience and Social Support Systems Among Early Adolescents: Applications of Latent Class Growth Analysis and Multiple-Group Growth Mixture Modeling
}

\author{
Hayoung Kim¹, Yu Jin Lee ${ }^{1}$, Yoonsun $\mathrm{Han}^{2}$ \\ Department of Child Psychology and Education, Sungkyunkwan University, Seoul, Korea ${ }^{1}$ \\ Department of Social Welfare, Seoul National University, Seoul, Korea ${ }^{2}$ \\ 초기 청소년의 탄력성 발달궤적 검증 및 사회적 지지체계 변화양상과의 관계: \\ 잠재계층성장분석(LCGA)과 다집단 성장혼합모형(GMM)을 이용한 종단연구 \\ 김하영 ${ }^{1}$, 이유진 ${ }^{1}$, 한윤선 ${ }^{2}$ \\ 성균관대학교 아동청소년학과 ${ }^{1}$, 서울대학교 사회복지학과 ${ }^{2}$
}

Objectives: Resilience is characterized by the ability to change over time and may increase or decrease in adolescence depending on available social support factors. In this study, we investigated trajectories of resilience and how these longitudinal patterns of resilience are related to changes in social relationships over time.

Methods: This longitudinal study analyzed 4,299 early adolescents from waves 3-6 (sixth year of elementary school to third year of middle school) of the Seoul Education Longitudinal Study (SELS). A latent class growth analysis (LCGA) was conducted to empirically demonstrate latent development trajectories of adolescents' resilience, and growth mixture model with known class was created to describe the relationship between resilience development trajectories and longitudinal change in social support systems (parent relationships, teacher relationships, peer relationships).

Resultts: First, the developmental patterns of adolescents' resilience varied over time; a total of six latent development trajectories were identified. The initial values of resilience by latent group were distributed over a wide range (high, middle-high, middle, middle-low, and low) and rate of change showed various patterns (decrease, decrease-increase, increase, and increase-decrease). Second, the patterns of change in social relationships (parents, teachers, peers) were similar to those of the resilience development trajectories. Third, among the three dimensions of social support, peer relationships showed the most similar patterns of change over time compared with other resilience development trajectories.

Conclusions: Based on the results of this study, differentiated interventions are required depending on the latent development trajectories of resilience, and adolescents should be provided with various opportunities to establish positive relationships with parents, teachers, and peers.

Keywords: resilience, social support systems, latent class growth analysis, multi-group growth mixture model

Corresponding Author: Yoonsun Han, Department of Social Welfare, Seoul National University, 08826, 1 Kwanak-ro, Kwanak-gu, Seoul, Korea E-mail: yshan@snu.ac.kr
(C)The Korean Association of Child Studies

This is an Open Access article distributed under the terms of the Creative Commons Attribution Non-Commercial License (http:// creativecommons.org/licenses/by-nc/4.0) which permits unrestricted noncommercial use, distribution, and reproduction in any medium, provided the original work is properly cited. 


\section{서론}

탄력성은 청소년이 가난, 질병, 학대, 방임, 폭력과 같은 상황 에서 겪게 되는 어려움을 극복하는 능력으로, 탄력성 발달은 심각한 역경이나 어려움의 상황 속에서 적응해가는 역동적인 과정이다(Wright, Masten \& Narayan, 2013). 이는 심각한 위협 이나 역경의 경험뿐만 아니라, 발달과정상 겪는 변화에 있어 서도 긍정적인 적응을 이루는 것을 포함한다(Luthar, Cicchetti, $\&$ Becker, 2000), 특히 탄력성은 개인이 직면한 변화에 잘 적응 하고 스트레스를 극복하는 수단이 됨과 동시에 미래에 다가올 스트레스에 대처할 수 있는 예방적 차원의 역할을 수행하기도 한다. 탄력성은 일상의 작은 스트레스에서도 계속적으로 작용 하여 우울, 불안, 공격성, 비행과 같은 심리사회적 부적응에 영 향을 미친다는 점에서 청소년 교육 및 임상 분야에서 중요성 이 강조되어 왔다(K. H. Kim \& Ju, 2013). 청소년기는 인간의 발달단계상 가장 많은 심리적, 신체적, 환경적 변화를 동반하 는 시기이며, 이 시기에 청소년이 겪는 대부분의 문제들은 과 도기적 특성을 가진다. 이를 잘 극복한 청소년은 안정적으로 성인기에 도달하지만, 그렇지 못한 청소년은 삶의 전반에 걸 쳐 지속적으로 어려움을 호소한다(Yoo, Lee, \& Jung, 2006). 탄 력성이 청소년들의 삶의 만족도에 장기적인 영향을 미친다는 관점에서(S. Kim \& Yoon, 2016), 탄력성은 역경을 경험한 청소 년에게만 국한 되는 것이 아니라 모든 청소년에게 중요한 요 소로 여겨진다.

탄력성을 연구하는 학자들은 탄력성에 대한 여러 가지 개 념정의를 시도하고 있다. 탄력성 연구 초반에는 탄력성을 크 게 2가지 관점에서 설명하였다(Rutter, 1990; Werner, 1993). 탄 력성을 개인의 고유한 특성으로 여기는 관점(Luthar, 1991)과 탄력성을 시간에 따라 변하는 역동적인 특성으로 정의하는 관 점이다(Masten et al., 1999; Rutter, 1985). 전자는 생물학, 신경 학, 사회생태학적인 관점에서 탄력성을 설명하고, 후자는 발 달경로에 초점을 맞추어 탄력성을 설명하였다. 최근에는 더 나아가 탄력성을 3 가지 관점에 따라 접근하고 있는데, 이는 개 인적인 특성으로 파악한 정신분석학적 관점, 시간에 따라 변 화하는 역동적 특성을 병리적 시각에서 살펴본 발달 정신병리 학적 관점, 탄력성은 시간과 연령에 따라 변화할 수 있으며 개 인의 특성과 주변 환경의 상호작용을 강조한 발달 맥락주의적 관점이다(Y.-S. Lee, 2015). 탄력성을 시간에 따라 변화하는 특 성으로 여기는 두 관점 중에서 먼저 발달정신병리학은 발달과 정에서 여러 가지 변화경로와 형태를 보이는 청소년의 적응 및 비적응적 행동에 중점을 둔다(Masten et al., 1999). 이 관점
은 위험요인들이 바로 특정 문제행동을 일으키는 것이 아니라 위험 요인이 적응기제를 구성하는 과정에 영향을 미쳐 부적 응이나 병리적인 결과를 초래한다고 보고(Whang, 1999), 청소 년의 발달과정에서 나타난 문제를 하나의 통합적인 인간발달 의 틀에서 바라본다. 그러나 본 연구는 다양한 사회적 맥락이 개인의 탄력성 변화에 영향을 끼친다는 선행연구들의 결과를 바탕으로(Y.-S. Lee, 2015; Markstrom, Marshall, \& Tryon, 2000), 발달 맥락주의적 관점에 초점을 맞추어 탄력성을 살펴보고자 한다. 발달 맥락주의적 관점에서는 적절한 사회맥락적 개입을 통해 개인의 탄력성 발달을 도모할 수 있다고 전제하는 것이 발달정신병리학과는 다른 특징이므로, 청소년의 올바른 성장 을 돕기 위한 방안을 모색하는데 적합하다.

발달 맥락주의적 관점에서는 탄력성이 발달 초기에 형성 된 후 불변하는 특성이 아니며, 처해진 환경에 따라 증진되 거나 쇠퇴할 수 있는 가변적인 특성을 지닌다(Block \& Block, 2006; Wicks, Hjern, Gunnell, Lewis, \& Dalman, 2005). Masten (2011)은 탄력성이 개인에 따라 다른 발달곡선을 그릴 수 있 다고 주장하였고, 탄력성의 발달유형을 총 7 가지로 제시하 였다. 7 개의 서로 다른 탄력성 발달곡선은 크게 4 가지의 변 화양상을 보이며 시간에 따라 탄력성이 증가하는 집단(1) positive transformation)과 탄력성이 감소하는 집단(2) delayed breakdown, (3) breakdown without recovery) 그리고 탄력성이 그대로 유지되거나(4) resistance, (5) unresponsive maladaptive pattern) 어느 시점동안 낮아졌다가 다시 회복하는 집단(6) disturbance with recovery, (7) persistent maladaptive)으로 나타났 다. 이러한 관점에서 탄력성은 극심한 스트레스를 경험하는 동안은 물론 개인의 전 생애 시기 동안 변화하며, 어떤 상황 에서는 탄력적인 청소년도 다른 상황이 되면 탄력적이지 못 할 수 있으므로 정적이라기보다는 변화하는 동적인 특성을 지 닌다(Block \& Kremen, 1996; Kaplan, 2005; Masten, Hubbard, Gest, Tellegen, Garmezy \& Ramirez, 1999).

또한, 발달 맥락주의적 관점은 인간의 성장과 발달을 이해 하는 데에 있어서 개인과 사회환경이 상호작용한다는 점에 주 목하여, 개인의 발달을 사회적 맥락과 동시에 고려한다는 것 이 특징이다(Lerner \& Kauffman, 1985). 선행연구들에서도 사 회적 요인들은 청소년의 탄력성에 유의한 영향을 끼치는 것으 로 확인되었다(Jung \& Lim, 2011; J. Kim \& Choi, 2014). 청소년 에게 타인과의 긍정적인 관계는 탄력성 증진에 중요한 역할을 하며, 사회적 지지체계는 탄력성을 향상시키는 요인으로 나타 났다(Demaray \& Malecki, 2002; S.-Y. Ju \& Lee, 2008; Masten et al., 1999). 급변하는 성장과정에 있는 청소년일지라도, 긍정적 
인 사회적 지지원을 가진 청소년은 역경에 올바르게 대처하고 극복할 수 있는 능력을 발달시킨다(Kang, 2006). 특히, 청소년 을 둘러싼 다양한 사회적 지지체계 중에서도 부모·교사.또래와 의 관계는 탄력성 발달에 높은 관련성을 가지는 것으로 나타나 (Garmezy \& Rutter, 1983; K. Lee \& Park, 2000; Werner \& Smith, 1982), 발달 맥락주의적 관점의 주장을 뒷받침한다.

먼저, 부모의 지지는 청소년에게 물질적, 정서적으로 필요 한 자원과 서비스를 제공하여 심리적 적응을 돕는 긍정적인 역할을 한다(S.-J. Lee \& Nam, 2008). 부모의 일관적인 양육방 식, 부모-자녀 간의 친밀성, 안정적인 가정의 분위기는 탄력 성 발달에 중요한 요인으로 여겨진다(Garmezy, 1993; Rutter, 1990). 부모-자녀관계는 출생 이후 첫 번째로 이루어지는 대인 관계이면서 가장 가까운 사회적 지지원으로서 (Kernis, Brown \& Brody, 2000) 부모의 양육태도는 탄력성 발달에 있어 매우 중요하다(K.-S. Kim \& Kim, 2011; D. Lee \& Yeom, 2015). 예를 들어 안정적인 부모-자녀관계는 탄력성의 발달을 도모할 수 있으나, 학대나 방임과 같은 불안정한 부모-자녀관계는 탄력 성의 발달을 저해시킨다(Chae \& Lee, 2007).

교육부의 연구에 따르면 청소년들은 하루 중 평균 8 시간 가 량 학교에서 보내고 있으며 교사와 끊임없는 상호작용을 하 는 것으로 나타났다(S.-H. Kim, Lee, Lee, \& Baek, 2014). 교사 와의 관계는 학생들의 발달에 큰 영향력을 끼칠 수 있으며(G. S. Yang \& Chang, 2001), 교사와의 유대감이 높은 청소년일수 록 스트레스나 위기상황에서 자기조절능력이 향상되고 문제 행동이 줄어드는 것으로 밝혀졌다(Block \& Kremen, 1996). 즉, 교사와의 지지적인 관계는 학생의 공격적인 행동을 억제시키 며 탄력성을 제고하는 역할을 하고(Birch \& Ladd, 1997), 교사 는 청소년들이 학교생활에 보다 잘 적응하고 성취를 높일 수 있도록 돕는 역할을 한다(Y. M. Kim \& Sim, 2000). 또한 가족 과의 관계에서 지지를 적게 받은 청소년에게 긍정적인 교사 와의 관계는 보완적 역할을 하게 된다는 연구 결과에 따라(E. Lee, 2000), 가정 내 위험에 노출된 청소년들에게 교사관계는 중요한 탄력성의 발달 요인으로 작용할 수 있다.

마지막으로 청소년기는 가족과 함께 보내는 시간보다 친 구들과 보내는 시간이 많아지고 친구에게 보다 의존하게 되 기 때문에 또래관계는 사회관계 중에서도 탄력성에 가장 강한 영향을 끼치는 것으로 나타났다(Y. J. Kim, 2012). 또래관계는 청소년의 자기 인식과 자아 개념 형성에 영향을 끼치고(W. G. Yang \& Doh, 1999), 정서적 안정, 사회적 성숙을 돕고 학교 스 트레스를 완충시키는 효과가 있다(Hwang \& Lee, 2012). 특히, 또래에게 수용되는 경험은 부모, 교사관계와 함께 탄력성에
정적으로 유의미한 영향을 끼친다(J. Kim \& Choi, 2014). 반면, 친구들에게 수용되지 못하고 배제 당한 청소년은 외로움이나 우울, 학교 부적응, 비행 등의 내재화 및 외현화 문제를 겪게 되어(Furman \& Robbins, 1985; Parker \& Asher, 1993) 탄력성 발달이 저해된다.

이처럼 선행연구들은 청소년의 탄력성 발달과 사회적 지 지체계와의 관계를 보고하고 있으나, 다음과 같은 세 가지 한 계점을 지니고 있다. 첫째, 탄력성이 여러 이론가들에 의해 시 간에 따라 변화할 수 있는 요인으로 여겨져 왔음에도 불구하 고(Masten et al., 1999), 청소년들의 다양한 탄력성 발달곡선 을 제시한 연구는 부재하다. 대부분의 탄력성 연구는 횡단적 관점에서 수행되어왔고, 종단적 관점을 취한 연구에서도 탄 력성의 다양한 발달곡선을 묘사하지 못한 한계를 지닌다(S. Kim \& Kwak, 2016; J.-H. Park, Kim, \& Jung, 2015). 따라서 여 러 유형의 탄력성 발달곡선이 존재할 수 있음을 고려함으로써 (Masten, 2011), 청소년들의 탄력성은 시간에 따라 어떤 변화 유형을 보이는지에 대한 구체적인 설명이 필요하다.

둘째, 선행연구들은 탄력성에 영향을 미치는 사회적 지지체 계를 단일 요인으로 접근하여 부모관계(Y.-J. Lee \& Park, 2005; $\mathrm{Um}, 2012)$, 교사관계(S. Ju \& Lee, 2012), 또래관계(Suk \& Park, 2009)를 개별적으로 살펴보았다는 한계를 지닌다. 탄력성에 대한 단일 요인과 그 작용에 대한 단편적인 시각은 한 개인의 변화를 예측하기에 부족하기 때문에, 사회적 지지체계의 여러 측면을 복합적으로 파악하고 비교하는 것이 필요하다. 부모, 교사, 또래의 지지는 청소년의 탄력성 발달에 위험요인이자 보호요인으로 작용할 수 있으므로(T. H. Kim \& Kim, 2004; J. $\operatorname{Kim} \&$ Yi, 2016; Kwak, 2018), 사회적 지지요인들의 영향을 통 합적으로 살펴볼 필요가 있다(Obradović \& Masten, 2007).

셋째, 종단적 관점에서 탄력성과 사회적 지지체계의 병행 적 흐름을 함께 고려한 연구가 부재하다. 탄력성과 사회적 지 지체계의 관계를 살펴본 선행연구는 크게 두 가지로 나누어 질 수 있는데, 탄력성만을 종단으로 살펴보았거나, 사회적 지 지체계만을 종단으로 살펴본 연구이다. 탄력성을 종단으로 본 연구에서는 한 시점에서의 사회적 지지체계만을 고려하여(J. B. Kim \& Park, 2018), 시간의 흐름에 따라 변화하는 탄력성과 사회적 지지체계를 함께 살펴보지 못하였다. 또한, 기존 연구 는 사회적 지지체계를 종단으로 보았으나 탄력성을 한 시점에 서 살펴보았거나(S. H. Chae \& Lee, 2007; Lim, 2013; Song \& $\mathrm{Kim}, 2012)$ 종단적 시차를 1년 미만으로 설정한 것으로(H.-T. $\mathrm{Kim}, 2011)$, 일반적인 탄력성의 변화 양상을 찾기 힘들다는 한 계가 있다. 


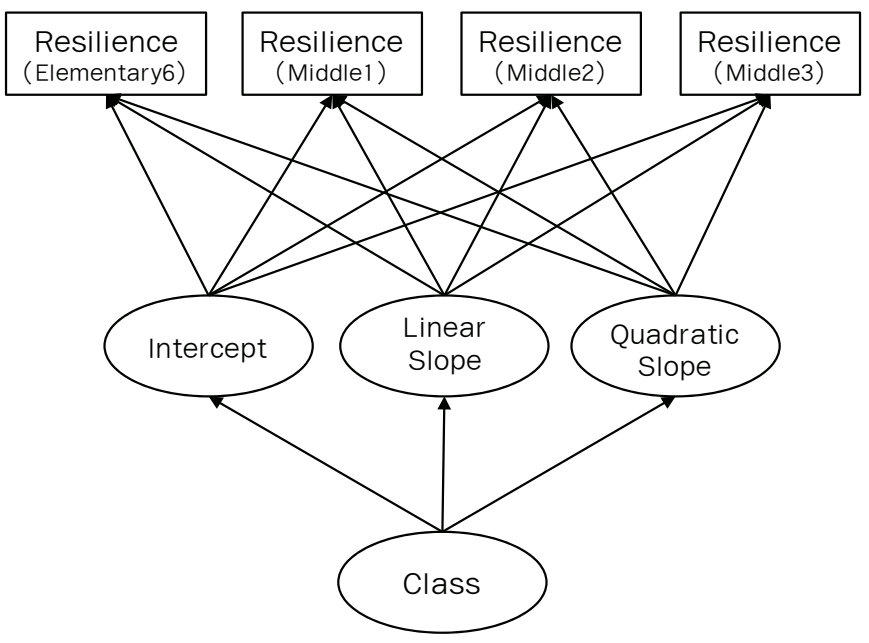

[Research Question 1]

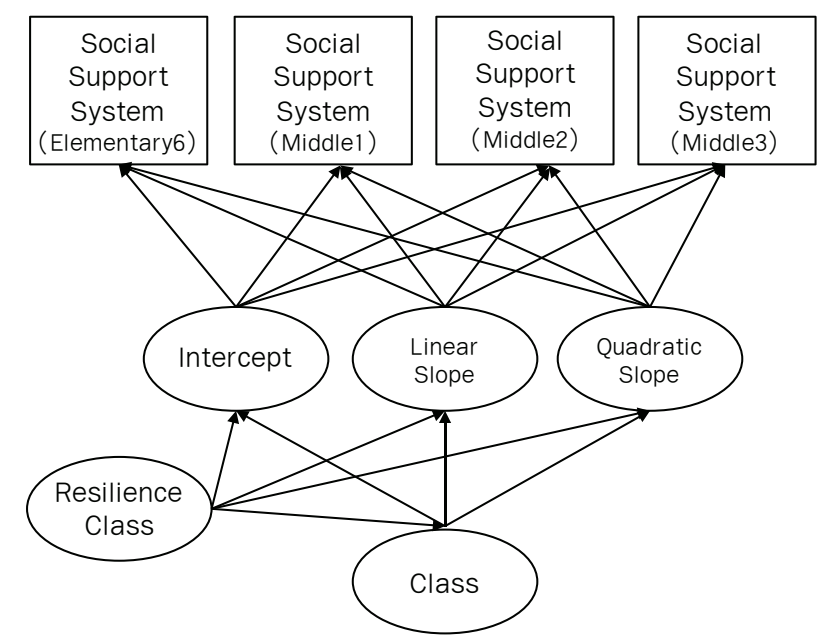

[Research Question 2]

Figure 1. Research model.

이와 같은 선행연구의 한계점을 보완하고자, 본 연구는 청 소년들의 다양한 탄력성 발달유형을 파악하고, 탄력성과 사회 적 지지체계와의 관계를 종단적으로 살펴보고자 한다. 이에 본 논문의 연구문제는 다음과 같다.

\section{연구문제 1}

시간에 따른 청소년의 탄력성 발달곡선은 몇 개의 잠재집단 으로 구분되며, 이들의 변화양상은 어떻게 나타나는가?

\section{연구문제 2}

각 탄력성 잠재집단에 따른 사회적 지지체계(부모관계, 교사 관계, 또래관계)는 시간에 따라 어떻게 변화하는가?

\section{연구방법}

\section{연구대상}

청소년기는 아동기에서 성인기로 전환하는 중요한 과정이다 (A. N. Park \& Kim, 2003). 특히 초등학교에서 중학교로 진학 하는 시기에는 학교에서 보내는 시간이 더 많아지고(Keum, Son, Chae, \& Kang, 2013) 교사, 또래와의 관계에서 많은 변화 를 경험하여 높은 수준의 스트레스를 받는 것으로 나타난다 (Y. H. Kim, 2010). 이러한 심리적 불안정은 탄력성 발달에 영 향을 줄 수 있으며, 초기 청소년 시기의 탄력성 변화양상을 살 펴 볼 필요가 있다. 이에 본 연구는 서울교육종단연구(Seoul
Education Longitudinal Study, [SELS])의 초등학교 4학년 패널 3-6차년도 자료를 사용하였다. 이는 집락추출방식으로 표집 된 서울지역 소재 초, 중, 고등학교의 학생들을 대상으로 2010 년부터 매년 추적 조사한 자료이다. 응답자는 초등학교 6학년 에서 중학교 3 학년에 해당하며, 주요 변인에서의 결측치를 제 외한 4,299명이 최종 분석에 활용되었다.

\section{연구도구}

\section{탄력성}

탄력성 변인은 학생들이 "(나는) 어려운 시기를 보낸 후에 빨 리 회복되는 편이다.”, “스트레스를 주는 사건을 별다른 문제 없이 견뎌낸다.", "어려운 일이 생겨도 잘 될 것이라 생각한 다.”의 문항으로 측정되었다. 각 문항은 5점 리커트 척도 (전혀 그렇지 않다[1점] 매우 그렇다[5점])로 평정되었으며, 분석 에는 세 문항의 평균값을 사용하였다. 초기 시점의 탄력성 문 항들의 Cronbach's $\alpha$ 값은 .86로 나타났다.

\section{사회적 지지체계}

부모관계 부모관계 문항은 학생들이 “(부모님은) 내가 공부 하는 것을 도와주신다.", "나와 많은 시간을 함께 보내려고 노 력하신다.”, "나를 잘 이해해 주신다.”를 포함한 총 13 문항으로 구성되어 있다. 모든 문항은 5점 리커트 척도(전혀 그렇지 않 다[1점] 매우 그렇다[5점])로 측정되었으며, 13 문항의 평균 
Table 1

Descriptive Characteristics of the Sample

\begin{tabular}{lrr}
\hline Variables & $M(\%)$ & $S D$ \\
\hline Gender & & $n$ \\
Male & $51.4 \%$ & 2,211 \\
Female & $48.3 \%$ & 2,078 \\
No response & $0.2 \%$ & 10 \\
Parent's education & & 4,083 \\
Elementary school & $0.4 \%$ & 16 \\
Middle school & $1.6 \%$ & 66 \\
High school & $37.3 \%$ & 1,521 \\
College (2-3 years) & $19.1 \%$ & 781 \\
University (4 years) & $35.9 \%$ & 1,467 \\
Graduate school (master) & $4.9 \%$ & 201 \\
Graduate school (doctoral) & $0.8 \%$ & 41 \\
Monthly household income (unit: 10,000 Korean won) & 505.95 & 3,853 \\
\hline
\end{tabular}

을 분석에 활용하였다. 부모관계 문항들의 Cronbach's $\alpha$ 는 .93 으로 높은 내적 일치도를 보였다.

교사관계 교사관계와 관련하여 학생들은 "(학교 선생님은) 학생들을 공정하게 대하신다.”, “말과 행동이 일치하신다.”, "학생들을 열심히 가르치려고 노력하신다.", "학생들의 생각 이나 행동을 잘 이해해 주신다.”의 문항에 응답하였다. 5점 리 커트 척도(전혀 그렇지 않다[1점] 매우 그렇다[5점])로 측정 된 4개의 문항의 평균을 분석에 활용하였고, 교사관계 문항들 의 Cronbach's $\alpha$ 는 .89로 나타났다.

또래관계 또래관계 변인은 "믿고 이야기할 수 있는 친구가 있 다.", “쉬는 시간이나 점심시간에 혼자 있기 보다는 친구들과 함께 지낸다.", “친구들과 서로 싸우더라도 금방 화해한다.”, “도움이 필요한 친구들을 도와준다.”로 구성되었다. 학생들은 5점 리커트 척도(전혀 그렇지 않다[1점] 매우 그렇다[5점])에 따라 보고하였고, 분석에는 4 문항의 평균을 사용하였다. 문항 간 내적 일치도인 Cronbach's $\alpha$ 는 .76으로 나타났다.

\section{분석방법}

본 연구는 먼저 초기 청소년의 탄력성에 대한 다양한 종단 적 변화를 살펴보고자 잠재계층성장분석(Latent Class Growth Analysis, [LCGA])을 실시하였다. 잠재계층성장분석은 개인 의 응답 패턴에 따라 유사한 응답자들을 하나의 집단으로 분
류하는 방법이다(Muthén \& Muthén, 2000). 표본을 분류하 기에 가장 적합한 잠재집단수를 제시하며, 변인이 아닌 개인 의 응답을 중심으로 이질적인 집단을 구분하는 것이 특징이 다. 잠재집단수의 결정에는 Akaike Information Criterion (AIC), Bayesian Information Criterion (BIC), Entropy, Lo-MendellRubin likelihood ratio test (LMR-LRT) 표본분포비율이 사용된 다. $\mathrm{AIC}$ 와 $\mathrm{BIC}$ 는 수치가 낮을수록 모형의 좋은 적합도를 의 미하고(Nylund, Asparouhov, \& Muthén, 2007), Entropy는 1에 가까울수록 높은 분류의 질을 의미한다(Hix-Small, Duncan, Duncan, \& Okut, 2004). LMR-LRT은 .05이하 값에서 통계적 유의성을 나타내며, 표본분포비율은 전체 표본 수의 $1 \%$ 이 상을 기준으로 한다(Hill, White, Chung, Hawkins, \& Catalano, 2000; Nooner et al., 2010).

두 번째, 탄력성의 잠재계층별로 살펴본 사회적 지지 수준 이 시간에 따라 어떻게 달라지는지 설명하기 위해, 다집단 성 장혼합모형(Growth Mixture Model with known clas; Muthén \& Muthén, 2012) 분석을 실시하였다. 다집단 성장혼합모형은 연 구자가 지정한 집단을 기준으로 집단별 성장혼합모형의 초기 치와 변화율을 제공한다(Kwon, 2014). 이에 본 연구는 잠재계 층성장분석을 통해 도출된 탄력성의 잠재계층을 집단으로 설 정하여, 잠재계층별 부모관계, 교사관계, 또래관계의 종단적 변화 곡선을 각각 살펴보았다. 사회적 지지요인의 그래프를 탄력성 발달곡선과 비교하여, 탄력성 발달곡선과 가장 유사한 양상을 보이는 사회적 지지원은 무엇인지 파악하였다. 모든 분석은 Mplus 8.0을 사용하여 시행하였다. 
Table 2

Descriptive Statistics of Major Variables

\begin{tabular}{|c|c|c|c|c|c|}
\hline Variable & Grade & $M$ & $S D$ & $F$ & Scheffe \\
\hline \multirow[t]{4}{*}{ Resilience } & Elementary6 (a) & 3.72 & 0.94 & $23.73^{* * *}$ & $\mathrm{a}>\mathrm{b}, \mathrm{c}, \mathrm{d}$ \\
\hline & Middle1 (b) & 3.63 & 0.05 & & \\
\hline & Middle2 (c) & 3.57 & 0.87 & & \\
\hline & Middle3 (d) & 3.58 & 0.86 & & \\
\hline \multirow[t]{4}{*}{ Parent Relationship } & Elementary6 (a) & 3.98 & 0.79 & $19.76^{* * *}$ & $\mathrm{a}>\mathrm{b}, \mathrm{c}, \mathrm{d}$ \\
\hline & Middle1 (b) & 3.9 & 0.79 & & \\
\hline & Middle2 (c) & 3.85 & 0.76 & & \\
\hline & Middle3 (d) & 3.88 & 0.75 & & \\
\hline \multirow[t]{4}{*}{ Teacher Relationship } & Elementary6 (a) & 4.12 & 0.79 & $156.42^{* * *}$ & $a>b, d>c$ \\
\hline & Middle1 (b) & 3.86 & 0.82 & & \\
\hline & Middle2 (c) & 3.75 & 0.79 & & \\
\hline & Middle3 (d) & 3.85 & 0.77 & & \\
\hline \multirow[t]{4}{*}{ Peer Relationship } & Elementary6 (a) & 4.32 & 0.63 & $5.17^{* *}$ & $\mathrm{~b}, \mathrm{c}, \mathrm{d}>\mathrm{a}$ \\
\hline & Middle1 (b) & 4.35 & 0.61 & & \\
\hline & Middle2 (c) & 4.36 & 0.6 & & \\
\hline & Middle3 (d) & 4.36 & 0.6 & & \\
\hline
\end{tabular}

${ }^{* *} p<.01 .{ }^{* * *} p<.001$.

\section{연구결과}

\section{인구통계학적 특성}

먼저 연구대상자의 인구통계학적 특성(Table 1)을 살펴본 결 과, 남학생과 여학생의 비율은 $51.4 \%$ 와 $48.3 \%$ 로 비교적 균등 하게 분포되어 있었다. 보호자의 최종 학력은 고등학교 졸업 (37.3\%)과 4년제 대학 졸업(35.9\%)이 가장 많았고, 월평균 가 계소득은 평균 505.95 만원 $(S D=586.27)$ 으로 나타났다.

\section{주요 변인의 기술통계량 및 분산분석}

본 연구에서 사용된 변인들의 기술통계량 및 분산분석 결과는 Table 2와 같다. 탄력성, 부모관계, 교사관계는 초기 3 년간 감 소하다가 마지막 해에 증가하였고, 또래관계는 4 년간 꾸준히 증가하였다. 학년에 따라 상이한 기술통계량이 나타났으므로, 주요 변인이 학년별로 유의한 차이가 존재하는지 검증하고자 일원배치 분산분석을 실시하였다. 그 결과, 학년별 탄력성, 부 모관계, 교사관계, 또래관계의 수준은 통계적으로 유의한 차 이가 있는 것으로 확인되었다. Scheffe 사후검정 결과, 탄력성, 부모관계, 또래관계에서는 초6이 다른 학년과 모두 통계적으 로 유의한 차이가 있었으며, 중학교 1-3학년 간에는 통계적으
로 유의한 차이가 나타나지 않았다. 교사관계에서도 초6이 다 른 학년과 모두 통계적으로 유의한 차이가 있었으며, 중1과 중 2 , 중 2 와 중3 간에도 통계적으로 유의한 차이가 존재하는 것 으로 나타났다.

\section{주요 변인 간 상관분석}

연구문제 검증에 앞서 청소년들의 탄력성과 사회적 지지요인 간의 관계를 살펴보기 위해 Pearson 상관분석을 실시하였다 (Table 3). 연도별 탄력성, 부모관계, 교사관계, 또래관계 간에 는 모두 유의한 정적 상관관계가 존재하는 것으로 나타났다. 탄력성과 사회적 지지체계의 상관계수는 또래관계 $(.25 \leq r \leq$ $.45, p<.001)$, 부모관계 $(.21 \leq r \leq .43, p<.001)$, 교사관계 $(.13 \leq$ $r \leq .29, p<.001)$ 순으로 확인 되었으며, 탄력성과 사회적 지지 체계 간에 유의한 관련성이 있음을 나타냈다.

\section{잠재계층성장분석(LCGA)에 의한 탄력성의 발달궤적}

초기 청소년의 다양한 탄력성 발달궤적을 파악하기 위해, 선 형 및 비선형 모형에서 집단수를 증가시키며 잠재계층성장분 석을 실시하였다(Table 4). 분석 결과, AIC와 BIC 값은 집단수 
Table 3

Correlations Among Resilience, Parent Relationship, Teacher Relationship, and Peer Relationship

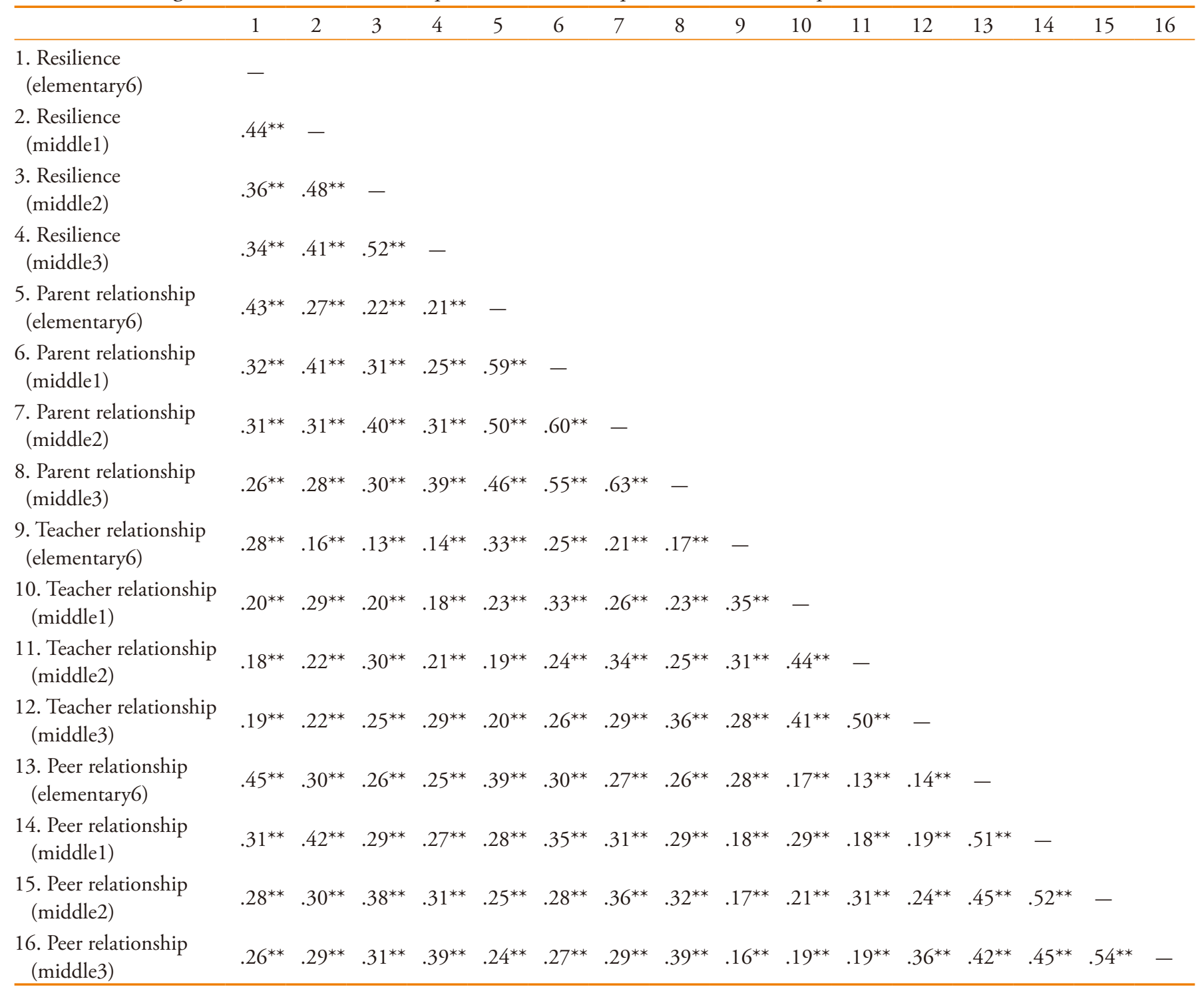
${ }^{* *} p<.01$.

가 증가함에 따라 꾸준히 감소하였으나, 비선형 6집단 모형에 서 가장 큰 폭의 감소를 보였다(Figure 2). 비선형 6집단 모형은 Entropy에 있어서도 가장 1 에 근접한 수치가 나타났고, 해당 모형의 모든 집단은 $1 \%$ 이상의 표본분포비율을 가지는 것으 로 나타났다. LMR-LRT의 값이 비선형 4집단 모형에서 통계 적 유의성을 만족하지 못하는 것으로 나타났으나, $\mathrm{AIC}, \mathrm{BIC}$, Entropy의 결과에서 공통적으로 비선형 6집단을 가장 적합한 모델로 제시하고 있으므로, 최종적으로 비선형 모델에서의 6 집단을 탄력성 잠재계층 수로 선정하였다.

최종적으로 도출된 6개의 잠재집단의 탄력성 발달곡선은
다음과 같다(Figure 3, Table 5). 첫 번째 집단인 상 집단( $\mathrm{I}=4.89$, $\mathrm{L}=-0.55, \mathrm{Q}=0.09, p<.001)$ 은, 전 시점에서 가장 높은 수준의 탄력성을 보였으며, 초기 청소년의 $21 \%$ 가 이 집단에 속하는 것으로 나타났다. 두 번째, $\mathrm{U}$ 자형 집단 $(\mathrm{I}=4.89, \mathrm{~L}=-2.25, \mathrm{Q}=$ $0.59, p<.001)$ 은 가장 역동적인 변화양상을 보이는 집단으로 청소년의 $3 \%$ 가 이에 해당한다. U자형 집단과 상 집단은 초기 에 동일한 탄력성 수준은 보였으나, 이후 U자형 집단은 탄력 성 수준이 급격히 감소하여 중학교 2학년 때는 전체 집단 중 탄력성이 가장 낮았고, 중학교 3학년 때 다시 증가하는 양상을 보였다. 가장 많은 청소년(38\%)이 속한 중상 집단 $(\mathrm{I}=3.95, \mathrm{~L}$ 
Table 4

Model Fit Indices

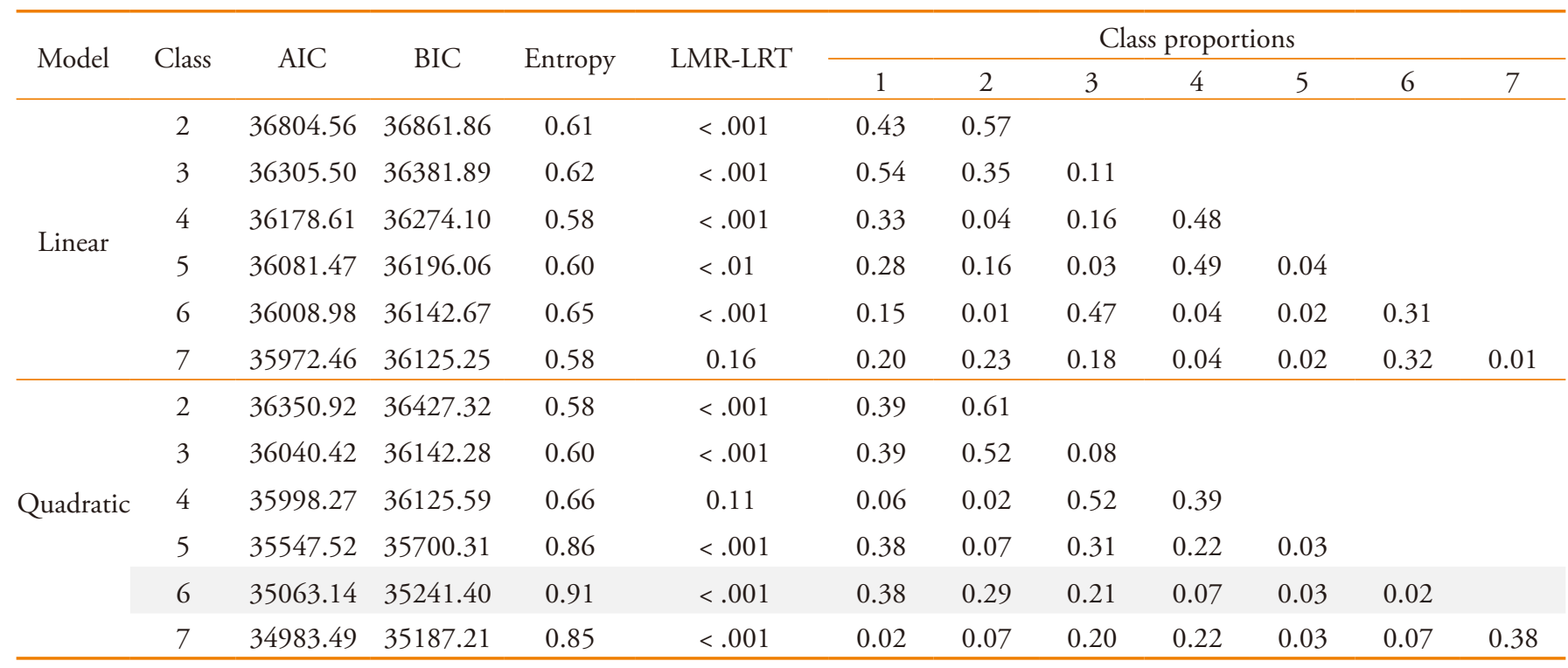

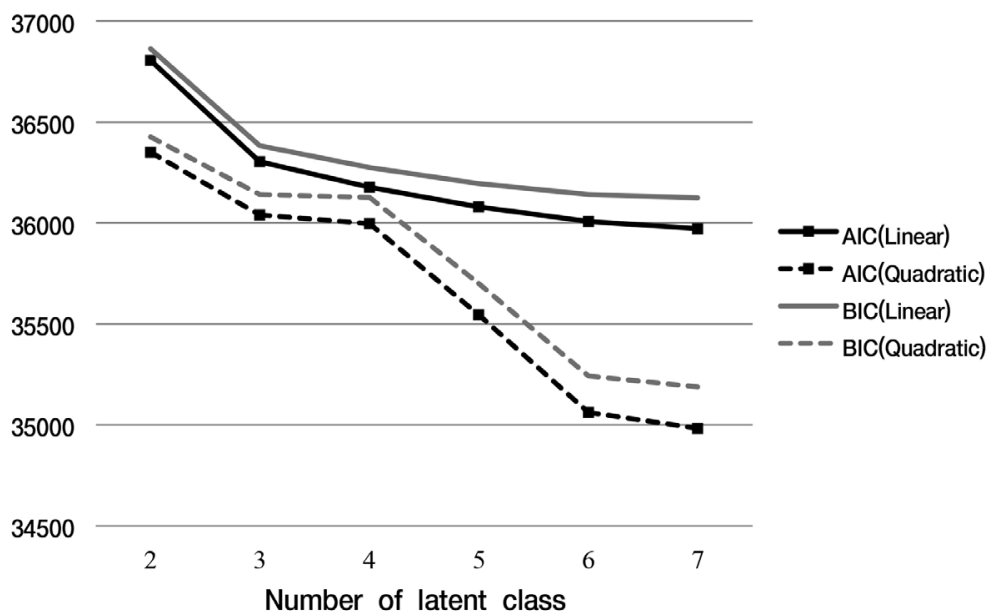

Figure 2. Model fit comparison between linear and quadratic trajectories.

$=-0.23, \mathrm{Q}=0.05, p<.001)$ 은 상 집단과 마찬가지로 탄력성이 다소 감소하고 있으나 다른 집단에 비해 4년 간 꾸준히 비슷한 수준을 유지하고 있었다. 두 번째로 많은 청소년(29\%)이 속한 중 집단 $(\mathrm{I}=3.05, \mathrm{~L}=0.25, \mathrm{Q}=-0.05, p<.001)$ 은 좁은 범위에 서 소폭 증가하는 양상을 보였다. 청소년 중 $7 \%$ 가 속해 있는 하 집단 $(\mathrm{I}=2.13, \mathrm{~L}=0.74, \mathrm{Q}=-0.14, p<.001)$ 은 다른 집단에 비해 낮은 탄력성 수준을 보이나, 꾸준히 증가하는 양상을 보 였다. 마지막으로, 역 U자형 집단 $(\mathrm{I}=1.21, \mathrm{~L}=1.58, \mathrm{Q}=-0.35$, $p<.001)$ 은 초기에 가장 낮은 탄력성 수준에서 급격한 증가 후
다시 감소하는 궤적을 보였고, 적은 수의 청소년(2\%)이 이에 해당하였다. 종합적으로 살펴보면 탄력성 잠재집단별 차이는 초등학교 6학년 때 가장 크고, 중학교 3학년으로 갈수록 그 폭 이 점차 줄어드는 것으로 나타났다.

\section{다집단 성장혼합모형(GMM)에 의한 사회적 지지체계의 변화양상}

두 번째 연구문제를 검증하기 위해, 탄력성의 잠재집단별 사 


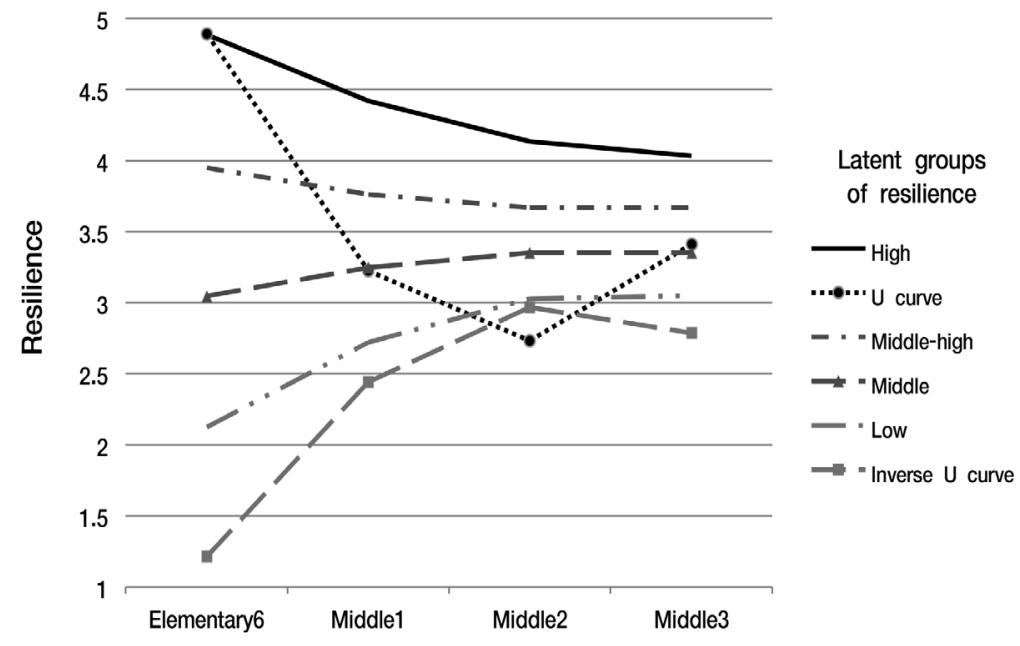

Figure 3. Developmental trajectories of resilience.

Table 5

Properties of the Six Latent Classes

\begin{tabular}{|c|c|c|c|c|c|c|}
\hline & \multicolumn{6}{|c|}{ Latent trajectories of resilience } \\
\hline Proportions & 0.21 & 0.03 & 0.38 & 0.29 & 0.07 & 0.02 \\
\hline Intercept (I) & $4.89^{* * *}$ & $4.89^{* * *}$ & $3.95^{* * *}$ & $3.05^{* * *}$ & $2.13^{* * *}$ & $1.21^{* * *}$ \\
\hline Quadratic slope (Q) & $0.09^{* * *}$ & $0.59^{* * *}$ & $0.05^{* * *}$ & $-0.05^{* * *}$ & $-0.14^{* * *}$ & $-0.35^{* * *}$ \\
\hline
\end{tabular}

${ }^{* * *} p<.001$.

회적 지지체계 변화곡선을 살펴보았다. 앞서 잠재계층성장분 석을 통해 도출된 탄력성의 발달궤적별로 부모관계, 교사관 계, 또래관계의 성장혼합모형을 검증하고, 각 곡선의 초기치 와 변화율을 확인하였다. 그 결과, 탄력성 잠재집단에 따른 4 년간 사회적 지지체계의 변화양상은 Figure 4 및 Table 6와 같 이 나타났다.

먼저 부모관계의 변화양상을 살펴보면, 상 집단, U자형 집 단, 중상 집단이 탄력성의 발달곡선과 유사한 변화양상을 보 이는 것으로 확인되었다. 초기치는 상 집단(I=4.47), U자형 집 단 $(\mathrm{I}=4.36)$, 중상 집단 $(\mathrm{I}=4.04)$, 중 집단 $(\mathrm{I}=3.71)$, 하 집단 $(\mathrm{I}=$ $3.46)$, 역 $\mathrm{U}$ 자형 집단 $(\mathrm{I}=3.24)$ 순으로 나타났으며, 모든 집단의 초기치는 통계적으로 유의한 것으로 나타났다 $(p<.001)$. 선형 및 이차항 변화율은 상 집단 $(\mathrm{L}=-0.19, p<.001, \mathrm{Q}=0.04, p<$ $.001)$, 중상 집단 $(\mathrm{L}=-0.13, p<.001, \mathrm{Q}=0.03, p<.001)$, 중 집단 $(\mathrm{L}$
$=-0.05, p<.05, \mathrm{Q}=0.02, p<.05)$ 에서는 완만하게 감소, $\mathrm{U}$ 자형 집단 $(\mathrm{L}=-0.67, p<.001, \mathrm{Q}=0.17, p<.001)$ 은 급격한 감소 후 증가, 하 집단 $(\mathrm{L}=0.02, p>.05, \mathrm{Q}=0.01, p>.05)$ 과 역 $\mathrm{U}$ 자형 집 단 $(\mathrm{L}=-0.10, p>.05, \mathrm{Q}=0.06, p>.05)$ 은 꾸준히 증가하는 것으 로 나타났다. 추가적으로, 중상 집단, 중 집단, 하 집단에서 초 기치 및 변화율의 분산이 통계적으로 유의하게 나타나, 세 집 단 내에는 유의한 개인차가 존재하는 것으로 나타났다.

다음으로, 교사관계의 변화를 살펴보면, 유일하게 U자형 집단 $(\mathrm{L}=-0.79, p<.001, \mathrm{Q}=0.21, p<.001)$ 만이 탄력성 발달 과 유사한 발달양상을 보이는 집단으로 나타났다. 교사관계의 초기치는 상 집단 $(\mathrm{I}=4.45, p<.001), \mathrm{U}$ 자형 집단 $(\mathrm{I}=4.38, p<$ $.001)$, 중상 집단 $(\mathrm{I}=4.16, p<.001)$, 중 집단 $(\mathrm{I}=3.92, p<.001)$, 하 집단( $\mathrm{I}=3.77, p<.001)$, 역 $\mathrm{U}$ 자형 집단( $\mathrm{I}=3.74, p<.001)$ 순 으로, 모두 통계적으로 유의하였다. 변화율에서는 집단마다 


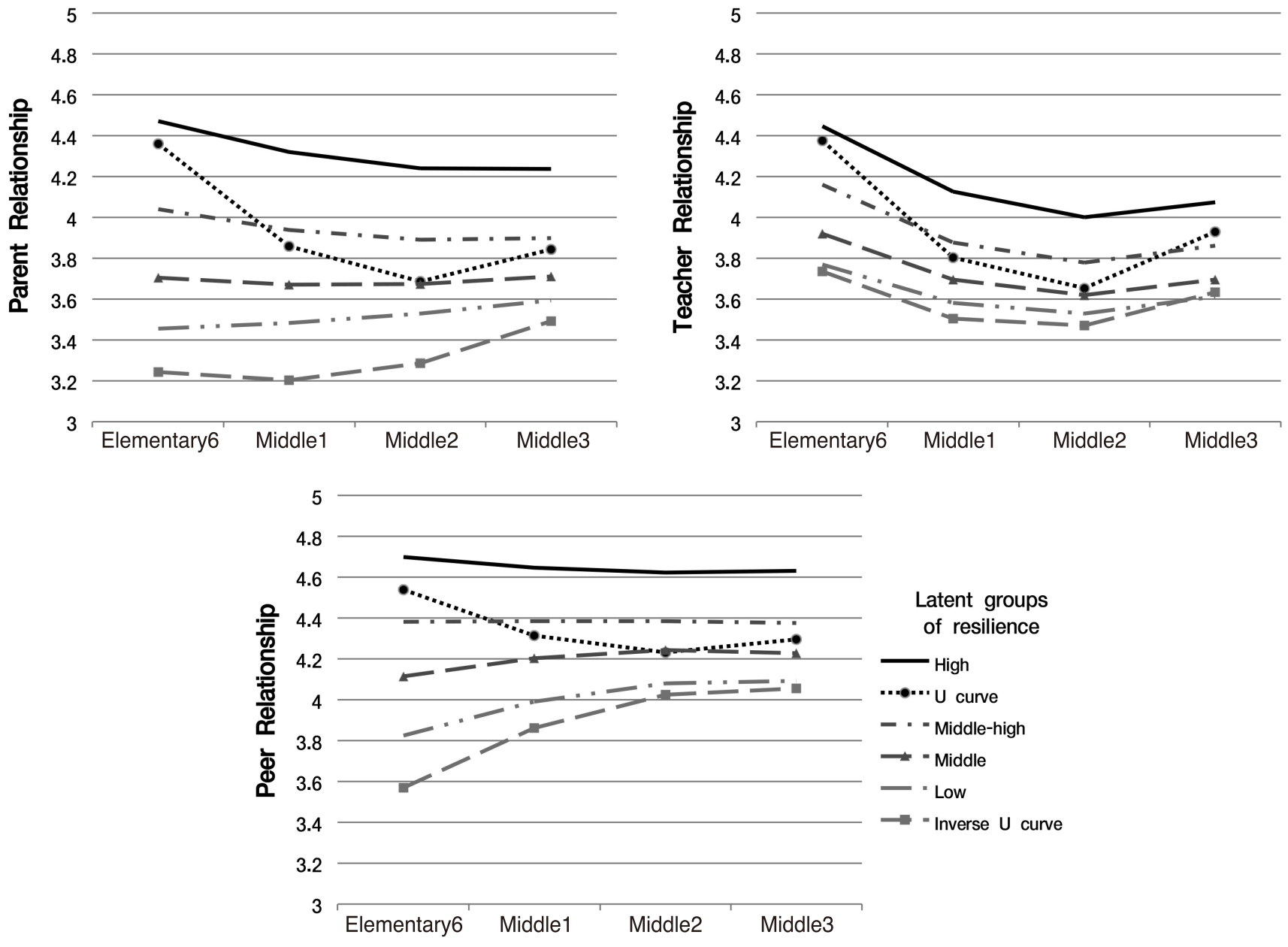

Figure 4. Changes in social support systems across the latent resilience groups.

각각 변화폭은 다르지만 공통적으로 중학교 2학년까지는 감 소하다가 중학교 3학년에서 증가하는 양상을 보였다. 그 중 중 상 집단과 중 집단의 초기치 및 변화율의 분산이 통계적으로 유의하여, 두 집단 내에 유의미한 개인차가 존재하는 것으로 나타났다.

마지막으로, 또래관계는 모든 집단에서 탄력성 발달과 유 사한 양상이 나타나, 탄력성과의 연관성이 가장 강한 사회적 지지원으로 나타났다. 또래관계의 초기치를 살펴보면, 상 집 단 $(\mathrm{I}=4.70), \mathrm{U}$ 자형 집단 $(\mathrm{I}=4.54)$, 중상 집단 $(\mathrm{I}=4.38)$, 중 집단 $(\mathrm{I}=4.12)$, 하 집단 $(\mathrm{I}=3.83)$, 역 $\mathrm{U}$ 자형 집단 $(\mathrm{I}=3.57)$ 순으로 모 두 통계적으로 유의미하게 나타났다 $(p<.001)$. 집단별 변화율 은 상 집단 $(\mathrm{L}=-0.07, p<.01, \mathrm{Q}=0.02, p<.05)$ 은 완만하게 감 소, $\mathrm{U}$ 자형 집단 $(\mathrm{L}=-0.30, \mathrm{p}>.05, \mathrm{Q}=0.07, p>.05)$ 은 급격한 감소 후 증가, 중상 집단 $(\mathrm{L}=0.01, p<.001, \mathrm{Q}=.003, p>.01)$ 은 유지, 중 집단 $(\mathrm{L}=0.12, \mathrm{p}<.01 \mathrm{Q}=-0.03, p<.001)$ 과 하 집단 $(\mathrm{L}$
$=0.21, p<.001, \mathrm{Q}=-0.04, p<.01)$ 은 꾸준히 증가, 역U자형 집 단 $(\mathrm{L}=0.36, p<.001, \mathrm{Q}=-0.07, p<.05)$ 은 급격한 증가 후 완만 한 증가를 보이는 것으로 나타났다. 초기치 및 기울기의 분산 은 중 집단에서만 유의하게 나타나, 중 집단 내 유의미한 개인 차가 존재함을 확인하였다.

\section{논의 및 결론}

청소년기에 탄력성은 끊임없이 변화하며, 청소년을 둘러싼 사 회적 지지체계는 탄력성의 변화에 긍정적이거나 부정적인 영 향을 끼친다. 하지만 탄력성의 가변성을 입증함과 동시에, 탄 력성과 사회적 지지체계 간의 변화양상을 함께 살펴본 연구는 부재하다. 이에 본 연구는 초기 청소년들의 다양한 탄력성 발 달곡선을 파악하고, 탄력성 발달곡선에 따른 사회적 지지체계 
Table 6

Properties of Social Support System Trajectories Across Latent Resilience Groups

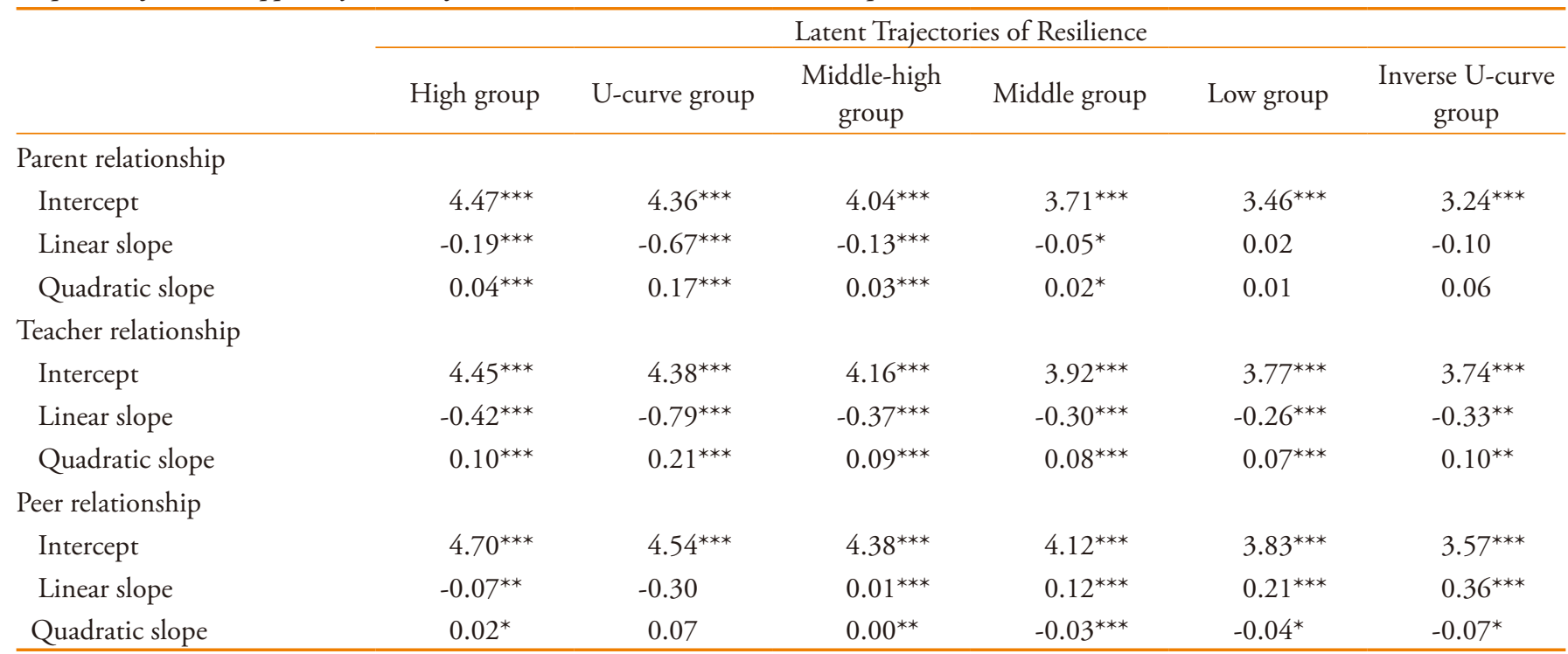

${ }^{*} p<.05 .{ }^{* *} p<.01 .{ }^{* * *} p<.001$.

의 변화양상을 살펴보고자 하였다. 청소년들의 탄력성의 변화 유형 파악에는 잠재계층성장분석(LCGA)을 사용하였고, 탄력 성 잠재계층별 사회적 지지체계의 변화양상은 다집단 성장혼 합모형(GMM with known class)을 통해 살펴보았다. 분석 결과 를 바탕으로 도출한 본 연구의 결론은 다음과 같다.

초기 청소년의 탄력성은 초기 시점과 변화율에 따라 6 개의 발달궤적이 존재하는 것으로 나타났으며, 선형보다는 이차곡 선에 가까운 변화양상을 띄고 있었다. 탄력성의 수준은 상, 중 상, 중, 중하, 하 수준에 걸쳐 다양하게 분포하였으며, 연령이 증가할수록 집단 간 편차는 줄어드는 양상을 보였다. 또한, 탄 력성의 시간에 따른 변화도 감소, 감소 후 증가, 증가, 증가 후 감소와 같이 다양하게 나타났다. 이는 청소년들이 4년 내에도 탄력성의 증가와 감소를 모두 경험할 수 있음을 보여주며, 더 나아가 개개인의 탄력성 발달곡선은 매우 다양할 수 있음을 유추해 볼 수 있다. 또한, 이와 같은 결과는 초기 청소년의 탄 력성은 시간에 따라 변화하며, 청소년들의 변화양상은 동일하 지 않고 다양한 양상을 보일 수 있음을 입증한 선행연구의 결 과를 뒷받침하고 있다(S. Kim \& Kwak, 2016).

부모, 교사, 또래는 청소년이 위기에 처했을 때 이를 잘 극 복할 수 있도록 물질적, 심리적 지지 체계로서의 역할을 한다. 이에 탄력성과 사회적 지지체계 간의 연관성은 여러 선행연구 를 통해 꾸준히 강조되어 왔다(Dumont \& Provost, 1999; Jung $\& \mathrm{Lim}, 2011 ;$ Y. J. Kim, 2012). 본 논문에서도 사회적 지지 수 준의 종단적 변화는 탄력성의 발달궤적과 유사한 양상을 보이
는 것으로 나타나, 탄력성과 사회적 지지체계의 관계를 지지 하고 있다. 다집단 성장혼합모형 검증 결과, 부모관계는 상 집 단, $\mathrm{U}$ 자형 집단, 중상 집단에서, 교사관계는 U자형 집단에서 탄력성 발달곡선과 유사한 변화양상을, 또래관계는 6 개의 집 단 모두에서 탄력성 발달곡선과 유사한 변화양상을 보였다. 즉, 청소년들에게 부모, 교사, 친구와의 관계는 탄력성에 단기 적인 영향을 줄 뿐만 아니라 지속적으로 탄력성 발달에 영향 을 줄 수 있음(Cicchetti \& Valentino, 2006; Clauss-Ehlers, 2003; Shin \& Son, 2016)을 입증하는 결과로 볼 수 있다.

탄력성 발달궤적과 사회적 지지체계의 종단적 관계 중에 서도, 또래관계의 변화가 탄력성의 발달과 가장 큰 연관성을 가지는 것으로 나타났다. 세 개의 사회적 지지체계 중 또래관 계의 변화곡선이 탄력성 잠재집단의 발달궤적과 가장 유사 한 양상을 보였다. 이는 청소년기에 들어서면서 부모나 교사 보다 또래를 애착과 친밀감의 대상으로 선호하며(Nickerson \& Nagle, 2004), 스트레스 상황에서 또래관계가 사회적 지지 요인으로서 부모나 교사보다 더 많은 영향을 준다(J. S. Park, 2011; Y. Park \& Kim, 2008)는 연구 결과들과 맥락을 같이 한다. 특히 또래와의 긍정적 관계를 형성한 청소년일수록 탄력성이 높고(Moon \& Baik, 2016), 탄력성이 높은 청소년일수록 긍정 적인 또래관계를 형성하는 것으로 나타나(Bae, 2017), 탄력성 과 또래관계는 지속적으로 서로 영향을 주고 받는 관계임을 알 수 있다. 즉, 초기 청소년의 탄력성 발달에 있어서 부모·교 사.또래 중 가장 우선적으로 고려되어야 할 사회적 지지원은 
또래관계임을 시사한다.

다만 본 연구는 집락추출방식을 활용하여 추출한 패널 데 이터를 분석에 사용하였으므로, 탄력성 발달에 영향을 끼칠 수 있는 청소년들의 개별 위기 경험에 대해 고려하지 못한 한 계를 지닌다. 본 연구에서 사용한 데이터로는 개개인이 위기 를 경험한 시점과 위기의 종류나 강도에 대한 정보를 파악할 수 없었으며, 추후 연구에서는 설문지에 위기경험에 대한 문 항을 포함한 양적 데이터의 활용이나 위기경험에 대한 인터뷰 를 포함한 질적 연구를 통해 개인의 위기상황을 고려한 탄력 성의 발달궤적을 파악하는 것이 필요하다. 또한, 본 연구는 사 회적 지지체계와 탄력성이 종단적으로 비슷한 양상을 보이고 있으며, 매 차년도마다 유의한 상관관계가 존재함을 밝혀냄으 로써 두 개념간의 관계를 탐색적으로 검증하였다. 다만, 이와 같은 사회적 지지체계와 탄력성의 종단적 변화 유사성과 상관 은 둘의 인과관계를 설명하기에는 어려움이 있으므로 연구결 과의 해석 및 적용에 주의가 필요하다. 이를 보완하기 위해서 는 자기회귀교차지연이나 잠재전이분석과 같이 두 개념간 종 단적 인과관계를 파악할 수 있는 분석방법을 적용하여 사회적 지지체계와 탄력성 간 인과관계에 대해 추가적으로 검증할 필 요가 있다. 마지막으로, 본 연구의 이론적 배경인 발달 맥락주 의적 관점에서는 개인 특성과 환경의 상호작용에 의해 탄력성 이 영향을 받을 수 있다고 언급하고 있다(Dyer \& McGuinness, 1996). 따라서 향후 연구에서는 개인의 기질과 주변 환경의 영 향이 적절한 조화를 이룰 때 탄력성 발달이 어떻게 나타나는 지 살펴볼 필요가 있다.

이와 같은 결론에 근거하여 청소년들의 탄력성 향상을 돕 기 위한 방안을 제안하면 다음과 같다. 첫째, 청소년들이 모두 동일한 탄력성 발달궤적을 보이는 것이 아니므로 우선적으로 개입이 필요한 탄력성 발달집단을 파악하고 각 집단의 특성 에 맞춘 차별화된 개입을 해야 한다(Masten, Powell, \& Luthar, 2003). 특히, 초기에 비해 탄력성이 급격히 감소하는 U자형 집 단과 가장 낮은 수준의 탄력성을 보이는 역U자형 집단에 해당 하는 청소년들을 우선적으로 파악할 필요가 있다. 이러한 청 소년들이 불안정한 탄력성 수준을 나타내는 원인을 파악하고, 이를 안정화시킬 수 있는 개입 프로그램 개발에 주력해야 한 다(Chun, 2006). 또한, 탄력성은 개인에 따라서도 다르게 나타 나지만 개인 내에서도 발달 단계에 따라 다르게 나타날 수 있 다는 점을 고려하여 장기적인 측면에서 프로그램을 계획하고 운영할 필요가 있다.

둘째, 탄력성 발달을 위해, 부모, 교사, 또래와 같은 사회 적 지지체계의 점검 및 개선을 위한 노력이 필요하다. 청소년
기는 부모, 교사, 또래와의 끊임없는 상호작용이 이루어지는 시기이며, 이러한 사회적 환경이 적절한 지지자로서의 역할 을 하지 못할 때 청소년에게 부정적 환경의 누적효과(pile-up effect)가 발생하여, 탄력성 발달이 저해된다고 강조한다(Jang, 2001). 따라서 청소년들의 사회관계형성 프로그램을 개발하 거나 상담 현장에서 개입 시 다양한 사회적 지지체계에 대한 이해를 바탕으로 맥락적 접근을 하는 것이 중요하다. 부모에 게는 청소년의 발달과정에서 요구되는 최적의 양육태도가 무 엇인지 교육하고, 교사들에게는 청소년의 탄력성의 증진을 도 울 수 있는 교육방식을 제공하여야 한다. 이와 더불어 청소년 들이 타인과의 상호 작용 기술을 습득하고 향상시킬 수 있는 효과적인 교육 프로그램의 개발이 필요하다(Bak, Lee, \& Song, 2010; H.-S. Park, 1999).

셋째, 청소년기의 탄력성 발달을 위해, 또래상담, 집단 활동 프로그램 등 또래와의 긍정적 관계를 형성할 수 있는 기회를 제 공하는 것이 더욱 중요시 되어야 한다. 본 연구에서 살펴본 다 양한 사회적 지지체계 중에서도, 또래관계가 청소년의 탄력성 발달과 가장 유사한 변화양상을 보였다는 결과에 따라, 또래관 계 개선을 통한 긍정적인 탄력성 발달을 기대해 볼 수 있다. 청 소년의 의사소통기술, 사회관계기술 등을 향상 시킬 수 있는 또 래 상담을 제공하고(Yang et al., 2014), 또래와의 관계를 강화할 수 있는 집단 활동 프로그램을 마련함으로써(Chu, 2013), 청소 년들의 탄력성 증진을 도울 수 있다. 특히, 최근 또래 간 학교폭 력 문제가 저연령화 및 심각화 현상을 보이고 있으므로, 청소년 의 또래관계에 대한 고민을 우선적으로 파악하고 이를 바탕으 로 탄력성을 높일 수 있는 대책을 강구해야 한다.

청소년의 탄력성 발달을 위한 개입은 단순히 청소년이 현 재 처한 상황에 대한 해결만을 목적으로 하는 것이 아니며, 장 기적인 관점에서 청소년의 스트레스가 비행이나 일탈행동으 로 이어지지 않도록 올바른 대처능력을 기르는 데 도움이 되 어야 한다. 따라서, 탄력성 발달집단과 사회적 지지체계를 고 려한 탄력성 역량을 개발지침을 마련함으로써, 청소년들이 탄 력적인 개인으로 성장하고 궁극적으로 안정적인 성인기로 진 입할 수 있도록 도와야 할 것이다.

\section{Acknowledgements}

This work was supported by the Ministry of Education of the Republic of Korea and the National Research Foundation of Korea (NRF-2016S1A5A2A03925702). 


\section{Notes}

This article was presented at the 2018 spring academic convention of Korean Association of Child Studies.

\section{Conflict of Interest}

No potential conflict of interest relevant to this article was reported.

\section{References}

\section{In English}

Birch, S. H., \& Ladd, G. W. (1997). The teacher-child relationship and children's early school adjustment. Journal of School Psychology, 35(1), 61-79. doi:10.1016/S00224405(96)00029-5

Block, J., \& Block, J. H. (2006). Venturing a 30-year longitudinal study. American Psychologist, 61(4), 315-327. doi:10.1037/0003-066X.61.4.315

Block, J., \& Kremen, A. M. (1996). IQ and ego-resiliency: conceptual and empirical connections and separateness. Journal of Personality and Social Psychology, 70(2), 349-361. doi:10.1037//0022-3514.70.2.349

Cicchetti, D., \& Valentino, K. (2006). An ecological-transactional perspective on child maltreatment: Failure of the average expectable environment and its influence on child development. In D. Cicchetti \& D. J. Cohen (Eds.), Developmental Psychopathology: Vol. 3. Risk, disorder, and adaptation (2nd Ed., pp. 129-201). Hoboken, NJ: John Wiley \& Sons. doi:10.1002/9780470939406.ch4

Clauss-Ehlers, C. C. (2003). Promoting ecologic health resilience for minority youth: Enhancing health care access through the school health center. Psychology in the Schools, 40(3), 265-278. doi: 10.1002/pits. 10086

Demaray, M. K., \& Malecki, C. K. (2002). The relationship between perceived social support and maladjustment for students at risk. Psychology in the Schools, 39(3), 305-316. doi:10.1002/pits. 10018

Dumont, M., \& Provost, M. A. (1999). Resilience in adolescents: Protective role of social support, coping strategies, selfesteem, and social activities on experience of stress and depression. Journal of Youth and Adolescence, 28(3), 343363. doi:10.1023/A:1021637011732

Dyer, J. G., \& McGuinness, T. M. (1996). Resilience: Analysis of the concept. Archives of Psychiatric Nursing, 10(5), 276-282. doi:10.1016/S0883-9417(96)80036-7

Furman, W., \& Robbins, P. (1985). What's the point? Issues in the selection of treatment objectives. In B. H. Schneider, K. H. Rubin, J. E. Ledingham (Eds.), Children's peer relations: Issues in assessment and intervention (pp. 41-54). New York: Springer. doi:10.1007/978-1-4684-6325-5_3

Garmezy, N. (1993). Children in poverty: Resilience despite risk. Psychiatry, 56(1), 127-136. doi:10.1080/00332747.1993.1 1024627

Garmezy, N. E., \& Rutter, M. (1983). Stress, coping, and development in children. Baltimore, MD: Johns Hopkins University Press. doi:10.1097/00004583-19900100000030

Hill, K. G., White, H. R., Chung, I. J., Hawkins, J. D., \& Catalano, R. F. (2000). Early adult outcomes of adolescent binge drinking: person-and variable-centered analyses of binge drinking trajectories. Alcoholism: Clinical and Experimental Research, 24(6), 892-901. doi:10.1111/ j.1530-0277.2000.tb02071.x

Hix-Small, H., Duncan, T. E., Duncan, S. C., \& Okut, H. (2004). A multivariate associative finite growth mixture modeling approach examining adolescent alcohol and marijuana use. Journal of Psychopathology and Behavioral Assessment, 26(4), 255-270. doi:10.1023/B:JOBA.0000045341.56296.fa

Kaplan, H. B. (2005). Understanding the concept of resilience. In S. Goldstein and R.B. Brooks (Eds.), Handbook of resilience in children (pp. 39-47). Boston, MA: Springer. doi:10.1007/978-1-4614-3661-4

Kernis, M. H., Brown, A. C., \& Brody, G. H. (2000). Fragile self-esteem in children and its associations with perceived patterns of parent-child communication. Journal of Personality, 68(2), 225-252. doi:10.1111/1467-6494.00096

Lerner, R. M., \& Kauffman, M. B. (1985). The concept of development in contextualism. Developmental Review, 5(4), 309-333. doi:10.1016/0273-2297(85)90016-4

Luthar, S. S., Cicchetti, D., \& Becker, B. (2000). The construct of resilience: A critical evaluation and guidelines for future work. Child Development. 71(3), 543-562. doi:10.1111/1467-8624.00164

Luthar, S. S. (1991). Vulnerability and resilience: A study of highrisk adolescents. Child Development, 62(3), 600-616. doi:10.1111/j.1467-8624.1991.tb01555.x

Markstrom, C. A., \& Marshall, S. K., \& Tryon, R. J. (2000). Resiliency, social support, and coping in rural low-incom appalachian adolescents from two racial groups. Journal of Adolescence, 23(6), 693-703. doi:10.1006/jado.2000.0353

Masten, A. S. (2011). Resilience in children threatened by extreme adversity: Frameworks for research, practice, and translational synergy. Development and Psychopathology, 
23(2), 493-506. doi:10.1017/S0954579411000198

Masten, A. S., Hubbard, J. J., Gest, S. D., Tellegen, A., Garmezy, N., \& Ramirez, M. (1999). Competence in the context of adversity: Pathways to resilience and maladaptation from childhood to late adolescence. Development and Psychopathology, 11(1), 143-169. doi:10.1017/ S0954579499001996

Masten, A. S., Powell, J. L., \& Luthar, S. S. (2003). A resilience framework for research, policy, and practice. In S. S. Luthar (Ed.), Resilience and vulnerability: Adaptation in the context of childhood adversities (pp. 1-16). New York: Cambridge University Press. doi:10.1017/CBO9780511615788.003

Muthén, B., \& Muthén, L. K. (2000). Integrating person-centered and variable-centered analyses: Growth mixture modeling with latent trajectory classes. Alcoholism: Clinical and Experimental Research, 24(6), 882-891. doi:10.1111/ j.1530-0277.2000.tb02070.x

Muthén, L. K., \& Muthén, B. O. (2012). Mplus HTML User's Guide. Seventh Edition. Los Angeles, CA: Muthén \& Muthén. Retrieved from https://www.statmodel.com/html_ ug.shtml

Nickerson, B., \& Nagle, R. (2004). Parent and Peer Attachment in Late Childhood and Early Adolescence. Journal of Early Adolescence, 25(-), 223-249. doi:10.1177/0272431604274174

Nooner, K. B., Litrownik, A. J., Thompson, R., Margolis, B., English, D. J., Knight, E. D., . . . Roesch, S. (2010). Youth self-report of physical and sexual abuse: A latent class analysis. Child Abuse \& Neglect, 34(3), 146-154. doi:10.1016/j.chiabu.2008.10.007

Nylund, K. L., Asparouhov, T., \& Muthén, B. O. (2007). Deciding on the number of classes in latent class analysis and growth mixture modeling: A Monte Carlo simulation study. Structural Equation Modeling: A Multidisciplinary Journal, 14(4), 535-569. doi:10.1080/10705510701575396

Obradović, J., \& Masten, A. S. (2007). Developmental antecedents of young adult civic engagement. Applied Developmental Science, 11(1), 2-19. doi:10.1080/10888690709336720

Parker, J. G., \& Asher, S. R. (1993). Friendship and friendship quality in middle childhood: Links with peer group acceptance and feelings of loneliness and social dissatisfaction. Developmental Psychology, 29(4), 611-621. doi:10.1037//0012-1649.29.4.611

Rutter, M. (1985). Resilience in the face of adversity: Protective factors and resistance to psychiatric disorder. British Journal of Psychiatry, 147(6), 598-611. doi:10.1192/bjp.147.6.598

Rutter, M. (1990). Commentary: Some focus and process considerations regarding effects of parental depression on children. Developmental Psychology, 26(1), 60-67. doi:10.1037/h0092669
Werner, E. E. (1993). Risk, resilience, and recovery: Perspectives from the Kauai Longitudinal Study. Development and Psychopathology, 5(4), 503-515. doi:10.1017/ S095457940000612X

Werner, E. E., \& Smith, R. S. (1982). Vulnerable but invincible: A study of resilient children. New York: McGraw-Hill

Wicks, S., Hjern, A., Gunnell, D., Lewis, G., \& Dalman, C. (2005). Social adversity in childhood and the risk of developing psychosis: A national cohort study. American Journal of Psychiatry, 162(9), 1652-1657. doi:10.1176/appi. ajp.162.9.1652

Wright, M. O. D., Masten, A. S., \& Narayan, A. J. (2013). Resilience processes in development: Four waves of research on positive adaptation in the context of adversity. In S. Goldstein and R. B. Brooks (Eds.), Handbook of resilience in children (pp. 15-37). Boston, MA: Springer. doi:10.1007/978-1-4614-3661-4_2

\section{In Korean}

Bae, M.-Y. (2017). A longitudinal study of developmental trajectories and predictors of peer attachment in early adolescence. The Journal of Child Education, 26(2), $207-$ 223. doi:10.17643/KJCE.2017.26.2.11

Bak, B.-G., Lee, S.-Y., \& Song, J.-H. (2010). Development of egoresiliency enhancement program and testing its effects. The Korean Journal of Educational Psychology, 24(1), 61-82.

Chae, S. H., \& Lee, J. S. (2007). The Relationship between the level of social-support and ego-resilience of elementary school students. CBNU Journal of Educational Research, 28(3), 149-167.

Chu, B.-W. (2014). Teaching methods for promoting adolescents' resilience in moral education. Journal of Ethics Education Studies, 34(-), 88-112.

Chun, E.-H. (2006). A study of resilience on the positive psychology perspective for child's successful life. Korean Journal of Child Welfare, 4(4), 141-156.

Hwang, H. J., \& Lee Y. N. (2012). The mediation effects of peer relations between parenting attitude and ego-identity. The Journal of Educational Research, 35(-), 25-52.

Jang, H. S. (2001). Resilience as a factor interrupting psychological disorders. The Korean Journal of Developmental Psychology, 14(1), 113-127.

Ju, S., \& Lee, Y. (2012). The roles of student-teacher attachment between latent delinquency, negative automatic thought and resilience in adolescents. Korean Journal of Youth Studies, 19(8), 103-142.

Ju, S.-Y., \& Lee, Y. (2008). Child maltreatment and resilience: Mediating effects of cognitive function and social support. Journal of Child Studies, 29(3), 127-156. 
Jung, J.-Y., \& Lim, J. (2011). Effects of temperament, family strength and social support on ego-resilience of adolescents. Korean Home Economics Education Association, 23(1), 3751.

Kang, H. K. (2006). Social supports and ego-resilience of children. Family and Environment Research, 44(11), 149-159.

Keum, J., Son, C., Chae, S.-E., \& Kang, S. (2013). Middle school students' school-adjustment, and the relation with family and individual characteristics. Korean Journal of Youth Studies, 20(2), 119-143.

Kim, H.-T. (2011). Longitudinal effects of social support, resilience and psycho-social adaptation of group home children. Korean Journal of Youth Studies, 18(11), 137-164.

Kim, J., \& Choi, M. (2014). Analysis of the structural relationship among family strength, social support, ego-resilience, hope, peer relational skills and problem behavior of adolescents. The Korea Journal of Youth Counseling, 22(1), 201-226.

Kim, J., \& Yi, K. (2016). A comparative analysis on determinants of resilience between general adolescents and adolescents in poverty. Korean Journal of Sociology of Education, 26(2), 3156.

Kim, J. B., \& Park, S. H. (2018). A study on school maladjustment of multicultural adolescents: Focusing on the longitudinal mediating effect of ego-resiliency. Journal of School Social Work, 41(-), 77-100.

Kim, K. H., \& Ju, H. J. (2013). The effects of children resilience on social problem-solving ability and psychosocial adjustment. Journal of Korean Council for Children \& Rights, 17(3), 437-457.

Kim, K.-S., \& Kim, H.-K. (2011). A study on relation between perceived parental rearing attitude and self-esteem and egoresilience of high school students. Journal of Educational Research, 19(2), 143-170.

Kim, S. (2012). The relationship of social relations and happiness in middle school boys and girls: Self-resilience and school adjustment mediating effects. Journal of the Korea Institute of Youth Facility and Environment, 10(4), 15-26.

Kim, S., \& Kwak, K. (2016). The effect of developmental change of children resilience on social competency. The Korean Journal of the Human Development, 23(4), 1-17. doi:10.15284/kjhd.2016.23.4.1

Kim, S., \& Yoon, K. (2016). Estimating adolescents' changes in life satisfaction: Tests of the effects of factors on individual differences in such changes. Studies on Korean Youth, 27(2), 271-296. doi:10.14816/sky.2016.27.2.271

Kim, S.-H., Lee, D.-Y., Lee, Y.-A., \& Baek, K.-S. (2014). An international comparison of elementary school curriculum: The cases of Korea, Canada, France, Finland, and Japan. Korean Journal of Comparative Education Society, 24(4), 157-179.
Kim, T. H., \& Kim, J. H. (2004). The effects of hope and meaning of life on adolescents' resilience. The Korean Journal of Counseling and Psychotherapy, 16(3), 465-490.

Kim, Y. H. (2010). The relation of daily stress and ego-resilience to the happiness of children and adolescents. Korean Journal of Youth Studies, 17(12), 287-307.

Kim, Y. J. (2012). The effect of social support on ego-resilience of group home adolescents. Journal of Transactional Analysis \& Counseling, 2(1), 1-22.

Kim, Y. M., \& Sim, H. O. (2000). Influences of communication with parents relations with teachers and intramural / extramural activities on peer relationships. Korean Journal of Child Studies, 21(4), 159-175.

Kwak, H.-S. (2018). Exploring factors affecting elementary students academic resilience. Journal of Learner-Centered Curriculum and Instruction, 18(3), 369-388. doi:10.22251/ jlcci.2018.18.3.369

Kwon, J. K. (2014). Analysis on the roles of group bullying in elementary school - profile exploration, prediction and longitudinal change analysis-. Journal of the Korean Society of Child Welfare, 45(-), 191-227.

Lee, D., \& Yeom, S. (2015). Multiple mediated effects of egoresiliency and depression in the relation between the affectionate parenting attitude and aggression. The Korea Journal of Youth Counseling, 23(2), 277-298.

Lee, E. (2000). Interactional effect of social support and self-esteem on juvenile delinquency. Korean Journal of Youth Studies, 7(1), 149-168.

Lee, K., \& Park, S. (2000). A study on the perceived stress and social supports of adolescent. Family and Environment Research, 38(9), 93-106.

Lee, S.-J., \& Nam, Y.-O. (2008). Effects of empowerment on school resilience of adolescents experienced family violence. Journal of Future Oriented Youth Society, 5(2), 63-82.

Lee, Y.-J., \& Park, K.-J. (2005). Stressful life experience and protective factors of resilient children. Korean Journal of Child Studies, 26(1), 329-345.

Lee, Y.-S. (2015). Comparing theoretical viewpoints about resilience. Korean Journal of Local Government \& Administration Studies, 29(1), 289-310. doi:10.18398/kjlgas.2015.29.1.289

Lim, Y.-M. (2013). Exploration of variables effecting on poor adolescents' self-resilience and self-esteem: Focusing on parents' child-rearing attitudes and the quality of peer and teacher relationships. Korean Home Economics Education Association, 25(2), 147-167.

Moon, S.-J., \& Baik, J. (2016). The effects of parent attachment and peer attachment on self-resilience and depression. Journal of the Korea Institute of Youth Facility and Environment, 14(3), 149-160.

Park, A. N., \& Kim, C. K. (2003). The effect of stress-coping 
training on the reduction of daily stress in children and strategies for coping with children's stress. Journal of Emotional \& Behavioral Disorders, 19(3), 257-281.

Park, H.-S. (1999). Effectiveness of program for increasing resilience of adolescents from unemployed families. Journal of the Korean Society of Child Welfare, 8(-), 35-58.

Park, J.-H., Kim, D.-J., \& Jung, S.-H. (2015). The functional effect of swimming exercise on the development of the ego resilience elementary school (Latent growth modeling analysis). The Korean Journal of Sport, 13(2), 203-215.

Park, J. S. (2011). The effect of social and internet participation on life satisfaction in early adolescents: focusing on mediating effects of sense of community. Journal of Adolescent Welfare, 13(4), 47-69.

Park, Y., \& Kim, U. (2008). The quality of life and interpersonal relationships among Korean adolescents. Korean Journal of Educational Psychology, 22(4), 801-836.

Shin, S.-J., \& Son, E.-Y. (2016). Longitudinal analysis of effects of parenting method and ego-resilience perceived by youth people on adaptation to school life: Focusing on the change between 4th grade and 7th grade. Korean Journal of Youth Studies, 23(12), 25-45. doi:10.21509/KJYS.2016.12.23.12.25

Song, M. \& Kim, S. (2012). The relationship among peer attachment, ego-resilience and mobile phone dependency in middle school students. Forum For Youth Culture, 32(1), 65-89.

Suk, J.-Y., \& Park, I.-J. (2009). The effects of peer attachment and ego-resiliency on the peer relationships of children from impoverished families: Comparison between two-parent families and single female parent families. Korean Journal of Family Welfare, 14(2), 29-50.

Um, I.-S. (2012). Research on the relationship between parentchildren communication and self resilience. Journal of Public Welfare Administration, 22(2), 51-70.
Whang, S. M. (1999). Developmental disorder, developmental psychopathology \& developmental intervention : The nature of clinical intervention program based on developmental view. The Korean Journal of Developmental Psychology, 12(1), 141-156.

Yang, G. S., \& Chang, S. S. (2001). A study on the characteristics of the protective factors for school resilience: On vocational high school students. The Korean Journal of Counseling and Psychotherapy, 13(3), 127-148.

Yang, M., Seo, M., Ju, J., Jeon, H.-H., Seong, B., \& Kim, H.-Y. (2014). The development of a peer counseling program for the prevention of school violence. The Korea Journal of Youth Counseling, 22(2), 363-381.

Yang, W. G., \& Doh, H. S. (1999). Relationships between peer acceptance, peer victimization and self-esteem in adolescents. Korean Journal of Child Studies, 20(1), 223238.

Yoo, A.-J., Lee, J.-S., \& Jung, H.-S. (2006). The effects of peer attachment and emotion regulation style on adolescents' depression. Journal of Korean Home Management Association, 24(1), 31-41.
Hayoung Kim Yu Jin Lee Yoonsun Han

\section{ORCID}

http://orcid.org/0000-0002-5633-1488

https://orcid.org/0000-0002-4538-8948

http://orcid.org/0000-0002-1108-0275
Received June 30, 2018

Revision received July 30, 2018

Accepted October 4, 2018 